\title{
Metabolic responses to recombinant bioprocesses in Escherichia coli
}

\author{
Sónia Carneiro*, Eugénio C. Ferreira, Isabel Rocha \\ IBB - Institute for Biotechnology and Bioengineering, Centre of Biological, Engineering, Universidade do Minho, Campus de Gualtar, 4710-057 Braga, Portugal
}

\section{A R T I C L E I N F O}

\section{Article history:}

Received 16 January 2012

Received in revised form 9 July 2012

Accepted 8 August 2012

Available online 26 September 2012

\section{Keywords:}

Recombinant proteins

Metabolism

High-throughput methods

Modelling

Systems biology

\begin{abstract}
A B S T R A C T
Escherichia coli has been widely used for the production of recombinant proteins. However, the unbalances between host metabolism and recombinant biosynthesis continue to hamper the efficiency of these recombinant bioprocesses. The additional drainage of biosynthetic precursors toward recombinant processes burdens severely the metabolism of cells that, ultimately, elicits a series of stress responses, reducing biomass growth and recombinant protein production.

Several strategies to overcome these metabolic limitations have been implemented; however, in most cases, improvements in recombinant protein expression were achieved at the expense of biomass growth arrest, which significantly hampers the efficiency of recombinant bioprocesses. With the advent of high throughput techniques and modelling approaches that provide a system-level understanding of the cellular systems, it is now expected that new advances in recombinant bioprocesses are achieved. By providing means to deal with these systems, our understanding on the metabolic behaviour of recombinant cells will advance and can be further explored to the design of suitable hosts and more efficient and cost-effective bioprocesses.

Here, we review the major metabolic responses associated with recombinant processes and the engineering strategies relevant to overcome these stresses. Moreover, the advantages of applying systems levels engineering strategies to enhance recombinant protein production in $E$. coli cells are discussed and future perspectives on the advances of mathematical modelling approaches to study these systems are exposed.
\end{abstract}

(c) 2012 Elsevier B.V. All rights reserved.

\section{Introduction}

Escherichia coli is one of the most used microbial systems for the production of recombinant gene products. The relatively inexpensive scaling-up and the versatility as a host have established this cellular system an attractive alternative to the production of protein drugs via non-microbial systems. Indeed, many products with pharmaceutical interest have been produced (under FDA approval) using E. coli, such as: human insulin, somatotropin, human parathyroid hormone or interferon alfa-2b (Ferrer-Miralles et al., 2009). The success of these products was essentially due to the ability to access a microbial platform that rapidly produces high-quality proteins in an efficient manner, maintaining the economic viability of these industrial processes.

However, some limitations still exist in these bioprocesses, particularly concerning the metabolic performance of host cells (Enfors et al., 2001; Konstantinov et al., 1991; Chou, 2007). The expression of recombinant products can challenge cells with different levels of toxicity and metabolic burden that, ultimately, can lead to the

\footnotetext{
* Corresponding author.

E-mail address: soniacarneiro@deb.uminho.pt (S. Carneiro).
}

decline of the biomass yield, productivity and cellular viability. Typically, cells counteract these effects by triggering stress-response mechanisms that adapt and readjust the metabolism so that cells can restore functionality and viability. However, these cellular responses represent themselves a significant deviation of cellular resources from growth and recombinant protein production. Therefore, the metabolic load imposed by the recombinant protein production and its main consequences in the whole metabolism of E. coli are quite relevant to consider when optimizing recombinant bioprocesses.

Currently, the ability to engineer microbial cells using recombinant DNA technology has provided us means to control the metabolism either by manipulating or introducing new enzymatic activities (Jeon et al., 2011; Zhu et al., 2011) or by interfering with regulatory interactions that ultimately influence metabolic activities (Demain and Adrio, 2008; Lee et al., 2005). Several reviews have been published summarizing the latest advances in genetic tools to enhance expression systems (Andersen and Krummen, 2002; Sorensen and Mortensen, 2005; Jana and Deb, 2005) and also, the developments in culturing processes using different microbial systems, including E. coli (Shimizu et al., 1988; Konstantinov et al., 1990; Hsiao et al., 1990; Seo et al., 1992). However, with the advent of systems-level engineering approaches and the 
application of multiple omics technologies, a new perspective over the improvement of microbial strains has arisen. Now, it is possible to characterize the recombinant systems at the system-level, which provide us with knowledge to engineer cells in a systematic manner, making these microbial strains more efficient and productive. The targeted manipulation of strains at the molecular level, together with the application of enhanced expression systems and suitable culture processes, can improve considerably the productivity of these microbial factories. In particular, by addressing the main metabolic limitations elicited during recombinant bioprocesses it would be possible to manipulate both the genetic background of the host cell and the culturing conditions in a controlled way to avoid any adverse activities.

This review will discuss the major metabolic responses associated with recombinant processes and the engineering strategies relevant to enhance the metabolic performance of recombinant E. coli host cells. We first review all the potential factors that induce metabolic perturbations during recombinant protein production in E. coli cultures and the main consequences on the metabolism of host cells. Then, we will review the main engineering strategies that have been successfully applied to manipulate the cellular metabolism to improve cells' physiology and the productivity of recombinant proteins. The potential of omics technologies in uncovering the main metabolic responses to recombinant processes will be presented, as well as the application of novel strategies based on systems-level analyses to manipulate the metabolic behavior of cells in a holistic manner.

\section{The metabolic burden in recombinant bioprocesses}

During recombinant protein production, cells are subjected to several physiological stresses, including the metabolic burden caused by drainage of metabolic precursors to the biosynthesis of heterologous proteins that is very aggressive to the metabolism of the host. The drainage of energy and biomass precursors, including amino acids and nucleotides toward the synthesis of recombinant material imposes severe alterations in the metabolism of host cells. Since the main biomass precursors are generally associated to glycolytic activities and the tricarboxylic acids (TCA) pathway, the disproportionate consumption of these metabolites leads to an imbalance in the central carbon metabolism.

According to several studies (Bentley et al., 1990; Corchero and Villaverde, 1998; Rozkov et al., 2004), the over-expression of heterologous proteins provokes a reduction in the synthesis of biomass-related proteins, due to the unequal competition for the translation apparatus by the mRNA species synthesised from the high-level expression of recombinant material. Moreover, as in most cases the amino acids composition of the recombinant protein clearly differs from the average composition of biomassrelated proteins, this will augment the metabolic imbalance in the host cells. Indeed, the effect of the amino acid content of recombinant proteins in $E$. coli growth rates has been evaluated by comparing the impact of the overexpression of peptides containing amino acids that are more and less abundant in the host (Bonomo and Gill, 2005). It was shown that cells expressing the peptide with less abundant amino acids became limited for those amino acids, which reduced protein synthesis that ultimately resulted in a lower growth rate. Similar studies have demonstrated the impact of codon usage bias in the expression of proteins (Zhou et al., 2004; Angov et al., 2008; Gustafsson et al., 2004; Kane, 1995). Heterologous genes containing codons that are rarely used in the host can cause ribosome stalling during translation at these specific codons, as the concentration of tRNAs for less-used codons is remarkably lower. Alternatively, amino acid substitution and possibly frameshifting can occur, which may introduce significant alterations in the structure of the recombinant protein. Either way, the effects on protein productivity and quality are critical. Further details are discussed in a recent review on the causes and consequences of codon bias (Plotkin and Kudla, 2011).

Also, it has been suggested that the recombinant plasmid alone burdens the metabolic capacity of cells (Bentley et al., 1990; Birnbaum and Bailey, 1991). Some of the building blocks and energy required to replicate plasmid DNA are intermediaries of the pentose phosphate (PP) pathway, e.g. ribose-5-phosphate and erythrose-4phosphate, which would impair the generation of NADPH and many other metabolic precursors like amino acids. NADPH participates mostly in biosynthetic reactions and, under normal growth conditions, over $60 \%$ is exclusively required for protein biosynthesis (Neidhardt et al., 1990). Therefore, the imbalance of this metabolic pathway would limit the availability of this reducing agent, and consequently reduce recombinant biosynthesis, as well as biomass formation.

Growth arrest and reduced protein synthesis are the most important effects of this metabolic stress (Bentley and Kompala, 1990; Glick, 1995), but many other effects have been described, such as the accumulation of undesired by-products like acetate (Eiteman and Altman, 2006). In general, the limitation or overaccumulation of some metabolic intermediaries changes the metabolic fluxes associated with these central pathways, which may induce cells to respond, either by restraining the activity of enzymes (either by enzymatic inhibition or transcriptional regulation) or by redirecting the metabolic fluxes through other pathways that lead to the accumulation of by-products. It has been reported that under recombinant protein producing conditions, cells lack immediate regulatory mechanisms for adjusting to a new balanced growth and can respond by destroying their ribosomes (Dong et al., 1995) or inducing the proteolysis of proteins (Rozkov et al., 2000; Rozkov and Enfors, 1999). More recently, a study on the ${ }^{13} \mathrm{C}$-labeling patterns of amino acids from a heterologous protein expressed in $E$. coli, revealed that cells react by reducing biomass formation and increasing energy generation through glycolytic activities (Pinske et al., 2011). In addition, the up-regulation of genes involving the transport of amino acids and energy storing compounds has been described, as well as the induction of enzymes associated with the biosynthesis of amino acids (Bonomo and Gill, 2005).

The ppGpp-mediated stringent response has also been associated with the metabolic burden caused by the over-expression of recombinant proteins (Bentley et al., 1990). This stress response is triggered by the accumulation of the alarmone ppGpp that controls gene expression by direct interaction with the RNA polymerase (RNAP) upon the intracellular depletion of amino acids (Artsimovitch et al., 2004; Chatterji et al., 1998). The downregulation of genes involved in the translational machinery and the up-regulation of stress-related proteins can explain the reduction of growth and protein synthesis frequently observed in recombinant cultures. The discovery that this guanosine nucleotide is accumulated during recombinant bioprocesses put forward the hypothesis of using ppGpp-deficient strains as hosts to improve the productivity of recombinant proteins (Dedhia et al., 1997; Carneiro et al., 2011b). Although some disadvantages in terms of the metabolic behaviour (e.g. failure to manage metabolic imbalances) exist, the enhanced protein production rate represents a major benefit in recombinant bioprocesses.

\section{Engineering strategies to overcome the metabolic burden in recombinant processes}

The latest advances in genetic engineering and fermentation methodologies allowed the optimisation of bioprocesses for the 
production of recombinant proteins using different cellular systems, especially bacteria like E. coli. This bacterium remains the primary choice for recombinant production, due to its simplicity, ease of manipulation, and low cost (Baneyx, 1999), but the limited metabolic efficiency of this cellular system places the industrial bioprocesses far from optimal. Hence the importance of understanding the impact of expressing heterologous proteins in the host cell metabolism.

Several groups have worked on developing strategies to overcome the metabolic burden in these biotechnological processes (Table 1). So far, optimisation strategies have been based on genetic modifications, both in the host genetic background and in the recombinant material or, in some cases, changes in the fermentation conditions, like the culture medium composition. However, most of these strategies have been based on empirical approaches that are quite time consuming and do not always result in the expected outcomes. Therefore, new strategies based on the rational design of microbial cells need to be explored. Up to now, only few attempts were made to understand and manipulate recombinant cells at the systems-level in order to obtain even more efficient systems, but with the development of mathematical modelling approaches and high throughput technologies, further advances are expected.

In the next subsections, reported strategies to overcome the metabolic burden in recombinant host cells will be discussed, namely: the genetic manipulation of recombinant material and the host genome and the control of culture conditions. Several excellent reviews describing general strategies for improving protein productivity have already been published (Demain and Vaishnav, 2009; Gnoth et al., 2008; Chou, 2007; Peti and Page, 2007; Jana and Deb, 2005; Sorensen and Mortensen, 2005; Andersen and Krummen, 2002). Therefore, we will focus primarily on the engineering of $E$. coli strains or the recombinant material that allowed to avoid (or overcome) the metabolic burden imposed by the protein synthesis. Some cultivation strategies used to improve the metabolic performance of host cells will be also exposed.

\subsection{Genetic engineering approaches}

\subsubsection{Engineering the recombinant material}

In general, expression vectors are the primary target to control recombinant production. Expression vectors are often based on naturally occurring plasmids that can be easily reconstructed to assemble parts from different genetic sources, such as control elements (e.g. promoters, terminators and transcription/translation initiation sequences) and propagation elements (e.g. selection markers, replication origins). The recent developments in the optimization of these elements have been widely covered in previous reviews (Sorensen and Mortensen, 2005; Chou, 2007; Jana and Deb, 2005; Baneyx, 1999), but their effects in the metabolism of host cells has been fairly discussed.

Many optimization strategies disregard the influence of these vector elements on the metabolic state of host strains and, consequently in the global performance of the recombinant process. Properties of a typical expression vector, like the plasmid copy number, the size of the plasmid, the gene marker and promoter strength, can contribute to the metabolic load imposed by the maintenance of recombinant DNA in host cells. Early studies on the effects of the plasmid content on the cellular growth (Jinho and Bailey, 1985; Birnbaum and Bailey, 1991; Bailey, 1993; Peretti and Bailey, 1987) have shown that the decrease in the biomass yield is one of the major responses to the large-scale production of plasmid DNA in E. coli. Bailey and co-workers (1990) have reported some studies on the effects of the plasmid copy number in the growth of host strains, showing that the plasmid DNA content per cell increases with the decrease of the cellular growth rate,
(Seo and Bailey, 1985; Seo and Bailey, 1986; Mason and Bailey, 1989). Although plasmid segregational instability could be implicated (Summers et al., 1993), in these studies no evidences were found, suggesting that these effects might be directly related with plasmid burden in host cells.

Another study with $E$. coli cells containing plasmids with the same size and expressing the same gene coding protein, but with increasing copy number, showed that the plasmid content is inversely correlated with the specific growth rate (Jinho and Bailey, 1985). Bentley and co-workers have also demonstrated that the plasmid copy number has a profound effect on the specific growth rates of the plasmid-bearing cultures, as well as the expression of plasmid-encoded proteins (i.e., growth rates changed from 0.45 to $0.23 \mathrm{~h}^{-1}$ when the expression of an plasmid-encoded protein, chloramphenicol acetyltransferases (CAT), increased approximately from 500 to $1800 \mathrm{U} / \mathrm{mg}$ ) (Bentley et al., 1990). It was assumed that the additional drainage of biosynthetic precursors to replicate and express the recombinant material burdens the host metabolism, such that the metabolic changes decreased the growth rate of plasmid-bearing cells. Many other studies have also suggested that the plasmid copy number is the principal factor for the metabolic burden associated with plasmid maintenance, resulting in significantly reduced growth rates (Jones et al., 2000; Corchero and Villaverde, 1998; Flores et al., 2004).

The promoter strength is also an important factor affecting the amount of recombinant transcripts produced in cells and thereby the host metabolism. From different sources and with different specificities (e.g. lac promoter from $E$. coli or T7 promoter from a bacteriophage that is specific to only T7 RNA polymerase), promoters have been chosen essentially by their transcription rates (Deuschle et al., 1986). Recently, engineering strategies that use promoter clusters consisting on multiple core-tac-promoters in the plasmid were tested to achieve high and stable gene overexpression (Li et al., 2012). However, the most efficient promoters might not be the best choice to improve recombinant bioprocesses, as the disproportionate increase of recombinant transcripts can overload the translational machinery and/or burden the metabolism of host cells. In, general, multicopy plasmids with foreign genes under the control of strong promoters are used to obtain high levels of expression of recombinant genes, but these two properties can induce detrimental effects on the host strain (Silva et al., 2012; Wang et al., 2006; Andersson et al., 1996; Rozkov et al., 2004; Neubauer and Winter, 2001).

Other factors, like the selection of antibiotic resistance markers may also contribute to the metabolic burden. For instance, genes for the resistance to kanamycin, chloramphenicol and ampicillin are normally expressed at high levels, while tetracycline resistance genes are expressed at lower levels (Glick, 1995). Antibiotic resistance markers can be also replaced by amino acid-auxotrophy complementation, i.e. by using auxotrophic strains transformed with a plasmid containing the gene that complements that auxotrophy, transformants are able to grow on minimal media without that amino acid supplementation (Vidal et al., 2008). These selection markers based on the amino acids auxotrophy are actually beneficial for the host cell, since the addition of antibiotics is abolished. Either selecting low level expressing genes for antibiotic resistance or auxotrophy complementation, the impact of recombinant biosynthetic activities over the metabolism might decrease.

Another strategy that has been proposed is the integration of the target gene sequence alone into the chromosomal DNA of the host organism (Chen et al., 2008). This would prevent cells to waste energy and metabolic resources to synthesize unneeded products, once antibiotic resistance markers are essentially used to maintain the stability of plasmid-bearing cultures. Though this seems promising, plasmid-based systems are still the most widely used, because they allow to obtain higher gene dosages and the genetic 
Table 1

Some examples of reported strategies to overcome the metabolic burden imposed by the expression of heterologous proteins in E. coli.

\begin{tabular}{|c|c|c|c|}
\hline & Strategies & Descriptions & Reference \\
\hline \multirow[t]{11}{*}{ Genetic modifications } & Low-copy number plasmids & $\begin{array}{l}\text { The use of plasmids with low copy number resulted in no significant } \\
\text { changes in cell growth. }\end{array}$ & (Jones et al., 2000) \\
\hline & Chromosomal insertion & $\begin{array}{l}\text { The chromosomal insertion of } 1-3 \text { copies of the lacZ gene revealed to } \\
\text { enhance the genetic stability compared to the plasmid expression } \\
\text { system under non-selective conditions (e.g., medium without } \\
\text { antibiotics). }\end{array}$ & (Chen et al., 2008) \\
\hline & Alternative selection markers & $\begin{array}{l}\text { The replacement of antibiotic gene markers by amino acid-auxotrophy } \\
\text { complementation in an E. coli M15-derivated glycine-auxotrophic } \\
\text { strain was tested, allowing to obtain high cell density cultures and } \\
\text { high productivity levels comparable to those obtained with the } \\
\text { conventional systems. }\end{array}$ & (Vidal et al., 2008) \\
\hline & $\begin{array}{l}\text { Alteration of transport } \\
\text { systems (I) }\end{array}$ & $\begin{array}{l}\text { A mutation in the ptsG gene encoding an enzyme of the glucose } \\
\text { phosphotransferase system (PTS) resulted in the reduction of acetate } \\
\text { excretion and, consequently biomass and recombinant protein } \\
\text { productivity were increased by more than 50\% compared to the } \\
\text { wild-type. }\end{array}$ & (Chou et al., 1994) \\
\hline & $\begin{array}{l}\text { Alteration of transport } \\
\text { systems (II) }\end{array}$ & $\begin{array}{l}\text { The replacement of the glucose phosphotransferase transport system } \\
\text { by galactose permease resulted in a reduced accumulation of acetate } \\
\text { and a concentration of recombinant protein almost four-fold higher. }\end{array}$ & (De Anda et al., 2006) \\
\hline & Engineering the PP pathway & $\begin{array}{l}\text { An } E \text {. coli strain carrying a high-copy number plasmid with the } z w f \\
\text { gene coding for the glucose- } 6 \text {-phosphate dehydrogenase enzyme that } \\
\text { participates in the pentose-phosphate (PP) pathway was used to } \\
\text { supply the extra demand of building blocks and energy required for } \\
\text { recombinant biosynthesis. The growth rate increased from } 0.46 \mathrm{~h}^{-1} \\
\text { (uninduced) to } 0.64 \mathrm{~h}^{-1} \text { (induced), which allowed to obtain a higher } \\
\text { recombinant productivity. }\end{array}$ & (Flores et al., 2004) \\
\hline & $\begin{array}{l}\text { Introducing new enzymatic } \\
\text { activities }\end{array}$ & $\begin{array}{l}\text { The alsS gene from Bacillus subtilis encoding the enzyme acetolactate } \\
\text { synthase was introduced into E. coli cells using a multicopy plasmid. } \\
\text { By introducing this new metabolic activity the excess pyruvate was } \\
\text { redirected away from acetate to acetolactate and then acetoin, } \\
\text { reducing the acetate accumulation and improving the recombinant } \\
\text { protein production. }\end{array}$ & (Aristidou et al., 1995) \\
\hline & Knockout of host genes (I) & $\begin{array}{l}\text { The ackA-pta-nuo mutant strain, which is deficient in acetate synthesis } \\
\text { (ackA-pta) and defective in the transmembrane NADH:ubiquinone } \\
\text { oxidoreductase (nuo) exhibited reduced acetate accumulation but also } \\
\text { significantly lower ethanol and formate synthesis }\end{array}$ & (Yang et al., 1999b) \\
\hline & Knockout of host genes (II) & $\begin{array}{l}\text { The } E \text {. coli } \Delta \text { pta mutant defective in phosphotransacetylase excreted } \\
\text { unusual by-products such as pyruvate, D-lactate, and L-glutamate } \\
\text { instead of acetate. }\end{array}$ & (Chang et al., 1999) \\
\hline & Knockout of host genes (III) & $\begin{array}{l}\text { A recombinant E. coli strain with deleted poxB-ackA-pta genes and } \\
\text { overexpressing the pyruvate dehydrogenase produced less acetate and } \\
\text { more isoamyl acetate (a valuable by-product) than the wild-type } \\
\text { strain. }\end{array}$ & (Dittrich et al., 2005) \\
\hline & $\begin{array}{l}\text { Overexpression of host } \\
\text { enzymes }\end{array}$ & $\begin{array}{l}\text { An E. coli strain with a fadR::Tn10 insertional mutation and } \\
\text { overexpressing the phosphoenolpyruvate carboxylase (PPC) enzyme } \\
\text { was used to test acetate accumulation. Results showed that acetate } \\
\text { yield is decreased more than fourfold compared to the control, while } \\
\text { the biomass yield is relatively unaffected }\end{array}$ & (Farmer and Liao, 1997) \\
\hline \multirow[t]{4}{*}{ Culture conditions } & Amino acid supplementation & $\begin{array}{l}\text { The coordinated amino acid feeding was shown to increase the } \\
\text { heterologous protein yield. }\end{array}$ & (Harcum et al., 1992) \\
\hline & Low glucose concentration & $\begin{array}{l}\text { Decreasing glucose concentration in the medium results in a reduced } \\
\text { accumulation of acetate and a higher recombinant productivity. }\end{array}$ & (Shiloach et al., 1996) \\
\hline & $\begin{array}{l}\text { Control of the specific } \\
\text { growth rate (I) }\end{array}$ & $\begin{array}{l}\text { Fed-batch and continuous cultures with } E \text {. coli JMI07 carrying a } \\
\text { plasmid pQRI26 with the } \alpha \text {-amylase gene were evaluated at different } \\
\text { specific growth rates (dilution rates) Recombinant production was } \\
\text { shown to be maximum at an intermediate rate of } 0.2 \mathrm{~h}^{-1} \text {. }\end{array}$ & (Turner et al., 1994b) \\
\hline & $\begin{array}{l}\text { Control of the specific } \\
\text { growth rate (II) }\end{array}$ & $\begin{array}{l}\text { Sophisticated feeding strategies in fed-batch cultures with } \\
\text { recombinant } E \text {. coli were developed to provide a fine control of the } \\
\text { biomass formation at a constant specific growth rate and limiting } \\
\text { acetate formation. }\end{array}$ & $\begin{array}{l}\text { (Gregory and Turner, 1993; } \\
\text { Turner et al., 1994a) }\end{array}$ \\
\hline
\end{tabular}

manipulations are easier and less time consuming compared to methodologies where genes are integrated into the chromosome. This may explain why only few methodologies for the insertion of heterologous genes into the host chromosome have been developed (Chiang et al., 2008; Martinez-Morales et al., 1999; Wei et al., 2010; Blaas et al., 2009; Chen et al., 2008).

Besides those strategies concerned with the engineering of expression vectors to reduce the metabolic burden in the host cells, together with the increase of protein expression levels, the redesign of coding-sequences of the target products has also been considered. The sequence of the translation initiation region and biases in the codon usage can reduce dramatically the translation efficiency of recombinant transcripts. Therefore, foreign gene sequences can impair the translational machinery of the host cells and elicit several stress responses that will contribute to the metabolic burden (Jana and Deb, 2005; Gustafsson et al., 2004; Kane, 1995; Schweder et al., 2002). Different strategies have been applied either by performing codon-optimization of the heterologous genes, according to the frequency of codon usage in the host (Burgess-Brown et al., 2008; Han et al., 2010; Hale and Thompson, 1998; Yang et al., 2004; Angov et al., 2008; Niemitalo et al., 2005), or through the co-expression of genes that encode the tRNAs that are scarce in 
the host (Calderone et al., 1996; Spanjaard et al., 1990; Saxena and Walker, 1992; Del et al., 1995). However, such approaches have shown some adverse effects, such as the lower specific activities of the target products due to unpredictable structural alterations (Gustafsson et al., 2004).

Other strategies targeting the gene sequence have also been exploited, but essentially related with protein stability, posttranslational modifications and the modulation of proteins activity. Although these are not directly related with the improvement of the metabolic performance of host cells, alterations can somehow influence the cell metabolism. For example, the design of a gene sequence without coding for any unnecessary amino acid residues reduces the drainage of biosynthetic resources. For protein stability, the replacement of cysteine by serine residues (O'Rourke et al., 1984; Doyle et al., 1985), as well as the deletion of the hydrophobic regions like N-terminal amino acyl residues (Hsu et al., 2006) have been successfully tested. In all of these assays the modified proteins showed increased stability and retention of activity. Other strategies have been applied to promote the secretion of proteins into the periplasmic space by fusion with coding sequences for a signal peptide (de Oliveira et al., 1999; Jonet et al., 2012).This significantly improves the recovery yield and product quality of recombinant bioprocesses, but problems associated with proteases attack and incorrect protein folding, which typically elicit various stress responses affecting the metabolism, are also avoided (Choi and Lee, 2004). Further approaches are discussed in (Kamionka, 2011).

The selection of the proper vector together with the use of codon-optimized genes in many instances may be adequate to allow the accumulation of the target protein at high levels, and, most importantly, reducing the impact of the metabolic burden in the host cell. However, the systematic application of different engineering approaches requires that the metabolic impact of heterologous gene expression can be predicted with a manageable set of variables. The metabolic behavior of host cells during recombinant production remains unclear, but many tools are being developed. With the advent of synthetic biology and the efficient de novo DNA synthesis, it is now anticipated a great potential for the systematic engineering of recombinant systems (Gustafsson et al., 2012).

\subsubsection{Engineering the host metabolism}

Still more attractive is the possibility to modify the efficiency of the host cell's metabolism by changing the expression of entire metabolic pathways or specific genes, either by increasing the gene dosage of rate-limiting enzymes or by deleting genes to convey the metabolic flux toward the production of desired metabolic intermediaries to balance the extra drainage of metabolic precursors to recombinant biosynthesis. The modulation of the central carbon metabolism has been explored to overcome the effects of metabolic burden during recombinant production. Strategies are predominantly related to carbon transport capacities (De Anda et al., 2006; Chou et al., 1994) and metabolic activities that supply for biosynthetic precursors, like amino acids, nucleotides and nucleosides (Flores et al., 2004).

Flores and co-workers (2004) showed that by increasing the expression of the $z w f$ gene, which codes for the first enzyme in the oxidative branch of the PP pathway, i.e. glucose-6-phosphate dehydrogenase, it is possible to overcome the bottleneck for the supply of building blocks (e.g. nucleotides) and reducing power (NADPH) that are required for plasmid replication and plasmidencoded protein expression. On the other hand, the replacement of the glucose phosphotransferase transport system (PTS) with an alternate glucose transport system, reduces the glucose uptake rate and, consequently, the levels of acetate excretion and improves the recombinant protein production over the wild-type strain (Lara et al., 2008; De Anda et al., 2006; Chou et al., 1994). Additionally, it was found that the benefits of replacing the phosphotransferase system (PTS) by other glucose transporters (e.g. glk and galP genes) can be augmented in $\triangle$ arcA phenotypes, allowing to enhance the glycolytic and respiratory capacities of the engineered strain (Flores et al., 2007). The problem of acetate accumulation in the medium during recombinant bioprocesses, especially under high cell density cultivations, has long been identified (Eiteman and Altman, 2006; Suarez and Kilikian, 2000). Acetate negative effects on growth of different recombinant $E$. coli strains have been tested (Koh et al., 1992) drawing attention to the importance of selecting suitable host strains and growth conditions that minimize acetate accumulation. In E. coli, acetate is synthesized mainly by the phosphotranscetylase acetate kinase pathway (Pta-AckA) using acetyl coenzyme A (AcCoA) as the substrate. Since AcCoA is primarily consumed via the tricarboxylic acid (TCA) cycle, only when an imbalance in this pathway occurs or the TCA capabilities are exceeded by the carbon flux through the glycolysis pathway (socalled overflow metabolism), the AcCoA is channelled to acetate biosynthesis (Xu et al., 1999; Castano-Cerezo et al., 2009; Chang et al., 1999). Although the phenomena that result in the accumulation of acetate during the production of recombinant proteins is not entirely clear, it is likely that the drainage of metabolic precursors to recombinant biosynthesis imbalances the TCA activity, increasing the intracellular accumulation of AcCoA and resulting in the production of acetate. It should be also mentioned that the amino acid composition of recombinant proteins has a major effect on the metabolic imbalances that may arise. If the recombinant protein sequence is rich in less abundant amino acids in E. coli, the precursors used to produce those amino acids will be the first to be depleted and fluxes around those precursors will change significantly. Thus, depending on the precursor becoming depleted, the channelling of fluxes through the accumulation of acetate will change. To exemplify, it is likely that if $\alpha$-ketoglutarate becomes deprived, TCA fluxes will decrease, accumulating AcCoA that will be channelled to the synthesis of acetate. The accumulation of acetate not only represents a deviation of carbon that might otherwise be used to generate energy and precursors for biosynthetic purposes, but it disrupts the proton motive force and impairs the cellular growth and the production of recombinant protein (Luli and Strohl, 1990; Eiteman and Altman, 2006). Thus, various strategies have been developed to overcome this metabolic phenomenon (Table 1) (De Anda et al., 2006; Eiteman and Altman, 2006; Kim and Cha, 2003; Shiloach et al., 1996; Suarez and Kilikian, 2000; Turner et al., 1994; Van de Walle and Shiloach, 1998; Wong et al., 2008). Genetic engineering methods like the direct knockout of genes encoding for enzymes in the biosynthetic pathway for acetate (e.g., ackA, pta and poxB) (Yang et al., 1999b; Chang et al., 1999; Dittrich et al., 2005; Tao et al., 2012) or the alteration of the level of gene expression in order to enforce the carbon flux through alternative pathways reducing acetate formation (Farmer and Liao, 1997) have been applied. For example, the over-expression of enzymes from anaplerotic pathways, like the phosphoenolpyruvate carboxylase (PPC), coupled with the deregulation of the glyoxylate bypass by using a $\Delta$ fadR strain was investigated (Farmer and Liao, 1997). The reduction in acetate accumulation was also achieved by expressing a heterologous gene from $B$. subtilis, the alsA that codes for an acetolactate synthase, which is capable to channel the excess of carbon to acetoin, a by-product less toxic than acetate (Aristidou et al., 1995).

Unfortunately, these engineered strains have shown to improve recombinant protein production still with low biomass growth associated, with large amounts of resources being driven to the formation of other by-products, such as lactate, pyruvate, acetoin and ethanol. This has still an impact on the product and biomass yields, making these strategies yet far from obtaining effective production systems. 
Since the effects of these genetic alterations were not considered at the systems-level, local perturbations can be propagated through the metabolic network in an unpredicted way. For instance, the increase of fluxes through the PP pathway may provide larger amounts of building blocks (e.g. nucleotides) toward the recombinant production, but it can also induce the accumulation of other metabolic intermediaries that exert an enzymatic control over central metabolic activities (Usui et al., 2012; Nicolas et al., 2007). As an example, the 6-phospho-D-gluconate that is an intermediary of the PP pathway can be over-accumulated and then exert an enzymatic inhibition over the enzyme phosphoglucose isomerase that catalyses the interconversion of glucose-6-phosphate and fructose6-phosphate (Schreyer and Bock, 1980). This can severely decrease the growth rate of $E$. coli cultures, as this activity is an essential step of glycolysis and gluconeogenesis pathways. When altering the metabolism of cells, it is important to consider the complex interconnectivity between pathways and, more importantly, to take into account that slight alterations in metabolite ratios induce immediate changes in the activity of enzymes.

\subsection{Culturing conditions}

The optimisation towards an efficient and robust recombinant production platform, includes the implementation of culturing conditions that attempts to minimize stresses during recombinant processes and further eliminate potential bottlenecks in the metabolism. One of the most simplistic approaches is the supplementation of amino acids that are limiting during the recombinant process (Harcum et al., 1992). However, this only solves the problem of the limitation of building blocks, while the limitation of energy generation persists. In addition, the supplementation of amino acids may exert unpredictable metabolic effects over the amino acid biosynthetic activities, since the enzymatic regulation of these pathways is primarily performed by the end-product, i.e. the amino acids (Lourenço et al., 2011). Only with a systematic approach that allows a holistic overview over these complex systems, it would be possible to fully understand the metabolic implications of these supplementation strategies.

Acetate formation is known to be strain-dependent (Son et al., 2011; Phue and Shiloach, 2004; Phue et al., 2005), i.e. for example $E$. coli BL21 reacts more efficiently to lower concentrations of acetate than the strain JM109, by reducing its specific glucose uptake. The choice of a more suitable strain can therefore be considered. Besides this, the accumulation of acetate is primarily connected to growth and carbon source uptake rates (Shiloach et al., 1996; Van de Walle and Shiloach, 1998). Therefore, high initial glucose concentrations will promote acetate formation, as well as cultivations at high specific growth rates. In turn, this results in the decrease of the specific production rate of recombinant protein (Turner et al., 1994). Accordingly, methodologies based on the control of nutrient feeding are valuable to prevent the overfeeding of media components that contribute to the metabolic overflow and the consequent accumulation of by-products that have an inhibitory effect in biomass growth (e.g. acetate), or to avoid the underfeeding in which cells become starved for limitingnutrients (e.g. carbon source). Feeding strategies can consist on the application of constant feeding rates, stepwise-increasing feeding rates or exponential feeding rates (with or without feedback control). The last one provides the advantage that by controlling the specific growth rate, acetate production can be minimized or even avoided (Rocha et al., 2008; Carneiro et al., 2011b; Gregory and Turner, 1993). However, by using advanced continuous cultivation methods (e.g. A-stat and D-stat), it was found that the specific growth rate is not the only mechanism controlling the central carbon metabolism in cultures (Valgepea et al., 2010); although most of the fermentation strategies are concerned to avoid acetate overflow by manipulating the specific growth rate, due to the detrimental effects on the carbon flow and energy spilling that leads to decreased protein productivity (as discussed above).

During recombinant bioprocesses, cellular responses like nutrient starvation can be elicited, which contribute to the metabolic stress of the host cells. Some of these responses may be associated with the cultivation mode. For example, high cell density cultures have long been preferred for recombinant fermentations with $E$. coli (Choi et al., 2006), but they can cause severe problems to the culture, such as substrate or oxygen limitations. These conditions may further contribute to the metabolic stress induced by recombinant processes and induce the expression of stress-responsive proteins that will compete for the translation apparatus and, more importantly for energy and metabolic sources, resulting in high productivity losses.

A major problem in large-scale recombinant E. coli cultures is the existence of gradients in dissolved oxygen tension (DOT). The effects of DOT gradients on the metabolic responses of cells and in the production of recombinant proteins have been studied (Sandoval-Basurto et al., 2005; Lara et al., 2006a). Losses in the biomass and protein yields and the accumulation of by-products like acetate, lactate, formate, and succinate, indicate that in oscillatory DOT cultures the deviation of carbon flow to fermentative pathways is significant. Moreover, the transcriptional responses showed that $E$. coli cells can respond very fast to intermittent DOT conditions, which suggests that rational scale-up criteria and strain design strategies should be established for improved culture performance at large scales. Further studies by Lara and co-workers (Lara et al., 2006b), have shown that fermentative pathways can be obviated as they are not necessary for bacterial survival during the short circulation times typical of large-scale cultures. By using different engineered E. coli strains (e.g. a $\Delta p o x B$ single mutant that eliminated the conversion of pyruvate into acetate; a $\Delta l d h \mathrm{~A} p f \mathrm{~B}$ double mutant unable to produce lactate and formate; and a $\Delta l d h \mathrm{~A} p f \mathrm{~B}$ poxB triple mutant) grown under oscillating DOT conditions it was found that the engineered cells were able to continue growing with improved specific growth rates and reduced by-product formation when compared to the parental strain.

Still concerning the improvement of fermentation processes to prevent oxygen limitation during growth in high cell density cultures, oxygen carriers like liquid perfluorochemicals that increase the oxygen transfer into cell cultures have been tested (Pilarek et al., 2011). In recombinant $E$. coli cultures, the cell density increased by $40 \%$ compared to control cultures and the amount of protein increased from 1.5 to 4.5 units. Many other recent fermentation strategies have been developed to provide high cell densities, high protein productivity per cell and good protein quality (Krause et al., 2010; Siurkus and Neubauer, 2011; Ukkonen et al., 2011); and most of them concern the improvement of the metabolic performance of host cells, even if indirectly. From conventional cultivations methods to new the systematically designed approaches, the ability to manipulate different variables has provided a faster and straightforward development of recombinant bioprocess.

Finally, the use of inducible expression systems and the moment of induction of the recombinant expression have been pointed as important factors to minimize the metabolic burden (Curless et al., 1990; Neubauer et al., 1992). The physiological state of the culture at the time of induction can affect the metabolic response to the recombinant process and, more importantly, its efficiency. If the induction is performed at the mid-logarithmic growth phase, cells can provide sufficient levels of energy and metabolic precursors for the recombinant biosynthesis, since the cell is at its maximum catabolic capacity. However, if induced at the late-logarithmic or stationary phase there is a higher cell density for product formation, but the metabolic state of the cells is unfavourable and the 
presence of stress-related proteins like proteases can reduce the yield of foreign proteins.

Hence, it is important to fine-tune the expression of recombinant proteins, the metabolic capabilities of the host cell metabolism and the cultivation conditions. The selection of cultivation modes that allow prolonging the production phase, at controlled growth rates and minimizing the induction of stress events is a suitable strategy to attain maximal yields of recombinant protein.

\section{Omics technologies as tools to elucidate the impact of recombinant processes}

Typically, the characterization of metabolic stresses during recombinant bioprocesses is done through the determination of physiological parameters, like growth yields or acetate accumulation. Although these are good indicators of the metabolic state of the cells, they do not reveal the extent of the metabolic perturbations in the entire biochemical network.

With the advent of omics technologies, such as transcriptomics, proteomics and metabolomics, it is now possible to evaluate the abundance of the main components involved in metabolic pathways. Changes in metabolite levels or alterations in the expression of enzymes can now be evaluated in a high-throughput manner. As metabolic networks are usually composed by numerous and highly interconnected components, a slight perturbation in a metabolite level affects the entire network and often these effects are difficult to predict. Therefore, a system-level perspective is needed to understand metabolic responses to different conditions, in particular during recombinant biosynthesis, and to identify potential metabolic targets that can be modified allowing an efficient supply for energy and metabolic resources toward recombinant protein synthesis.

The DNA microarray technology (i.e., transcriptomics) has been widely used to characterize changes in the transcriptional patterns when inducing the recombinant protein expression in E. coli cells (Choi et al., 2003; Duerrschmid et al., 2008; Haddadin and Harcum, 2005; Oh and Liao, 2000). In most studies, a large number of transcripts displayed statistically significant changes upon the induction of the recombinant protein, from which those involved in key metabolic activities, such as amino acid biosynthesis, acetate synthesis and transport (in particular, the glucose phosphotransferase system) were found to be up-regulated. Glycolytic and TCA genes were not affected significantly, but presented consistent down-regulated expression levels, which explains the decrease in the metabolic activity of cells encountered during recombinant protein overproduction. The scrutiny of these results has already led to the implementation of genetic engineering strategies to improve recombinant protein production. For example, Choi et al. (2003) co-expressed the prsA gene to further supply precursors for the synthesis of purines, pyrimidines and amino acids. This decreased the specific growth rate of the recombinant culture, but the protein content was 2.3 times higher than that obtained without the co-expression of the prsA gene. This indicates that transcriptome profiling can assist in the selection of target genes to be overexpressed or deleted to achieve a desired goal. However, the evaluation of results from these analyses should consider the complexity of these biological systems, as it is often difficult to predict how the system will react to certain genetic changes.

Similarly, proteomics studies have been explored to examine the global physiological changes in E. coli during the production of recombinant proteins (Duerrschmid et al., 2008; Lee et al., 2007; Wang et al., 2005; Aldor et al., 2005). As expected, differential expression levels of proteins were detected when comparing producing and nonproducing cells, in particular the downregulation of proteins involved in the central carbon metabolism (e.g. glycolysis, PP pathway and TCA cycle) and the up-regulation of cell protection proteins and some sugar transport proteins. In an attempt to investigate the PP pathway as a potential metabolic bottleneck for the improvement of recombinant protein production, Wang et al. (2005) have engineered E. coli BL21(DE3) to overproduce the phosphogluconolactonase (PGL) enzyme from Pseudomonas aeruginosa, in order to increase the metabolic flux through the PP pathway. As a result, a higher growth rate and biomass yield were observed, as well as the up-regulation of proteins participating in the tricarboxylic acid (TCA) cycle, suggesting that the supplementary PGL activity was valuable to overcome limitations in the supply of reducing power and precursors for high level protein synthesis.

Proteomic profiling can also provide a valuable tool to hypothesize metabolic targets to make these systems more robust, but as referred before, these results only offer information relative to changes of a single level of the system under specific conditions. The combination of different levels of information and predictive computational tools has been started to provide valuable insights to understand these systems.

As proteomics data correlates to a certain degree with transcriptomics data, the combination of these two technologies can be included in integrative approaches (Duerrschmid et al., 2008; Yoon et al., 2003). For example, the protein profiles obtained from difference gel electrophoresis (Ettan(TM) DIGE) and the transcriptome profiles from total microarrays were evaluated to monitor stress responses during recombinant protein expression in E. coli chemostat cultures. This study showed fairly good correlations between data (approximately $35 \%$ to $56 \%$ ), whereby seven proteins showed consistent expression levels, such as: the DnaK and IbpA chaperones; the proteins involved in the cell movement and chemotaxis FlgK and FliC; the TCA cycle enzymes AceA and IdH; and the cell division protein FtsZ.

Metabolomics, one of the newest omics technologies being developed, has provided the determination of the abundance of hundreds of metabolites simultaneously. Since metabolite levels are the closest link between the metabolic status and the phenotype of cells, information provided by these analyses is useful to examine the metabolic and cellular changes in cells during the production of recombinant proteins. Metabolomics studies have revealed that, besides increased fluxes of overflow pathways, especially acetate synthesis, the glyoxylate shunt, not active during growth, was utilized during recombinant production, probably to minimize the uncoupling of the glycolytic and TCA activities (Wittmann et al., 2007). Surprisingly, other studies revealed that upon the induction of recombinant protein expression there is a rapid accumulation of unexpected metabolites outside of the cell, such as malonate and cis-aconitate (Carneiro et al., 2011b). The immediate secretion of isocitrate lyase inhibitors, such as cis-aconitate, suggests that the anaplerotic glyoxylate shunt is activated to replenish the TCA intermediaries that were withdrawn toward the formation of recombinant protein.

The metabolic burden was also quantified through the determination of intracellular fluxes using ${ }^{13} \mathrm{C}$-based metabolic flux analysis (Heyland et al., 2011). Though this methodology is still limited by the information available on the organism's metabolic network, for recombinant $E$. coli it was possible to determine fluxes through the TCA cycle, which were fairly constant, and acetate synthesis that increased with the increasing amount of the inducer added to the culture.

The information extracted from omics analyses is invaluable to examine the physiological changes occurring during these processes (Oh and Liao, 2000; Haddadin and Harcum, 2005; Duerrschmid et al., 2008; Lee et al., 2007; Wittmann et al., 2007). In Fig. 1, the main metabolic responses covered by reported omics analyses are illustrated, together with some examples of genetic 


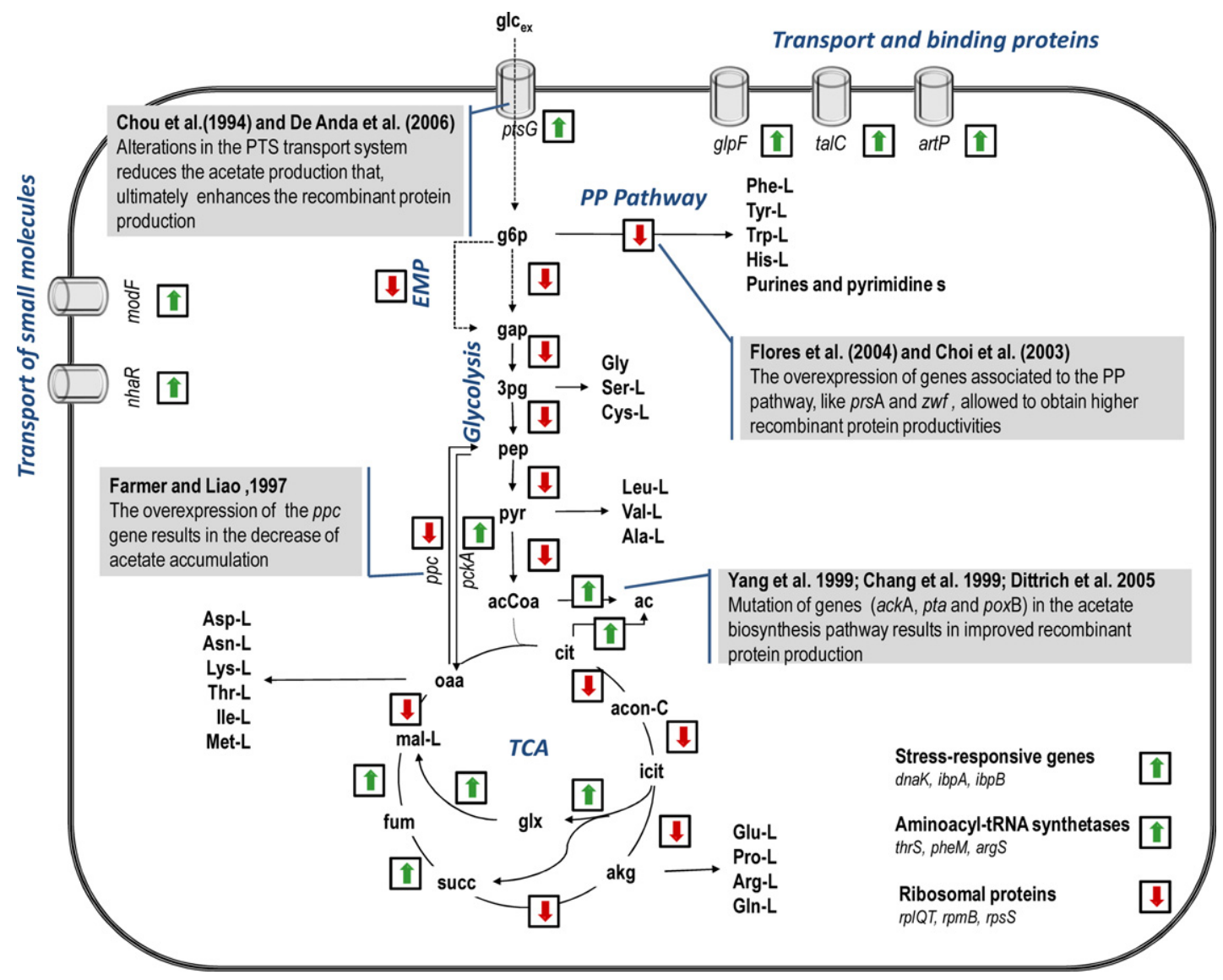

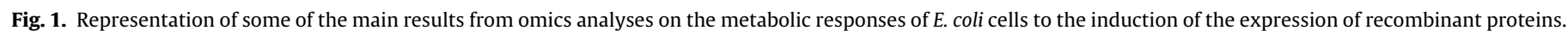

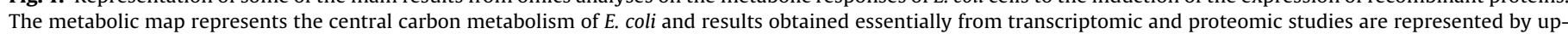

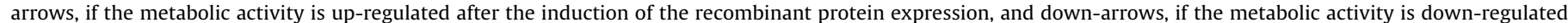

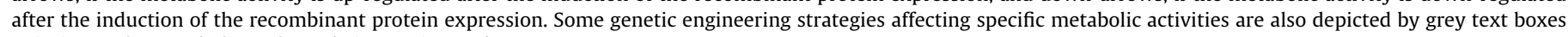
pointing to the metabolic pathway being engineered.

engineering strategies that were implemented in the last years to overcome metabolic limitations. However, the potential of these tools to rationally design microorganisms with desired metabolic activities has rarely been explored, in particular for the production of recombinant proteins in microbial cells (Park et al., 2005; Han et al., 2011). It is important to render these omics analyses into integrated tools of existing systematic approaches to predict new engineering targets or to re-design fermentation strategies that otherwise would be much harder.

\section{Advancing recombinant bioprocesses through systems biology}

As previously presented, the majority of the reported strategies has enabled the improvement of protein production at reasonable levels, but often at the expense of biomass growth. This makes recombinant bioprocesses less efficient and profitable, as the biomass yield and the volumetric productivity are major factors in the production and downstream processing of these microbial fermentations. Although some strategies have been focused on the adjustment of the metabolic capacities of microbial cells to overcome some limitations during recombinant processes, this has not been done at a systematic level, which implies that detrimental changes can be provoked in the cellular metabolism.

Typically, these adjustments were achieved by simplistic trialand-error methodologies (or empirical approaches) that were carried either by introducing or replacing metabolic activities from other organism sources (De Anda et al., 2006) or by enforcing or removing existing metabolic activities (Eiteman and Altman, 2006; Wong et al., 2008). These methodologies allowed to increase the formation of metabolic precursors that become limiting during recombinant processes, but in some cases the growth rate recovery was only partial, with the carbon flux being channelled to the formation of metabolic by-products (Yang et al., 1999a; Aristidou et al., 1995). To avoid this metabolic waste it is crucial to employ new strategies that account for the structure and functionality of the entire metabolic network, therefore overcoming the negative impact of the genetic changes performed (the so-called systematic approaches) (see Fig. 2).

Metabolic engineering has emerged as a successful tool to direct the metabolic behaviour of cells into more efficient systems (Yu et al., 2011; Bulter et al., 2003; Aristidou et al., 1995; Covert et al., 2001). In this approach the metabolic capabilities of cells are considered an integrated system and their functional properties, like enzymatic and regulatory interactions and even the network topology are taken into account when re-designing metabolic networks. This way, promising targets that maximize the formation of the desired products and prevent ineffective alterations in the metabolism can be found.

Stoichiometric-based models have been explored to study the metabolic behaviour of microbial cells and to predict phenotypes that optimize the production of target metabolites. In more detail, metabolic networks can be represented by stoichiometric models that are usually simulated by constrained-based approaches, termed flux balance analysis (FBA), assuming a steadystate of the metabolism and a metabolic objective (e.g. growth rate 


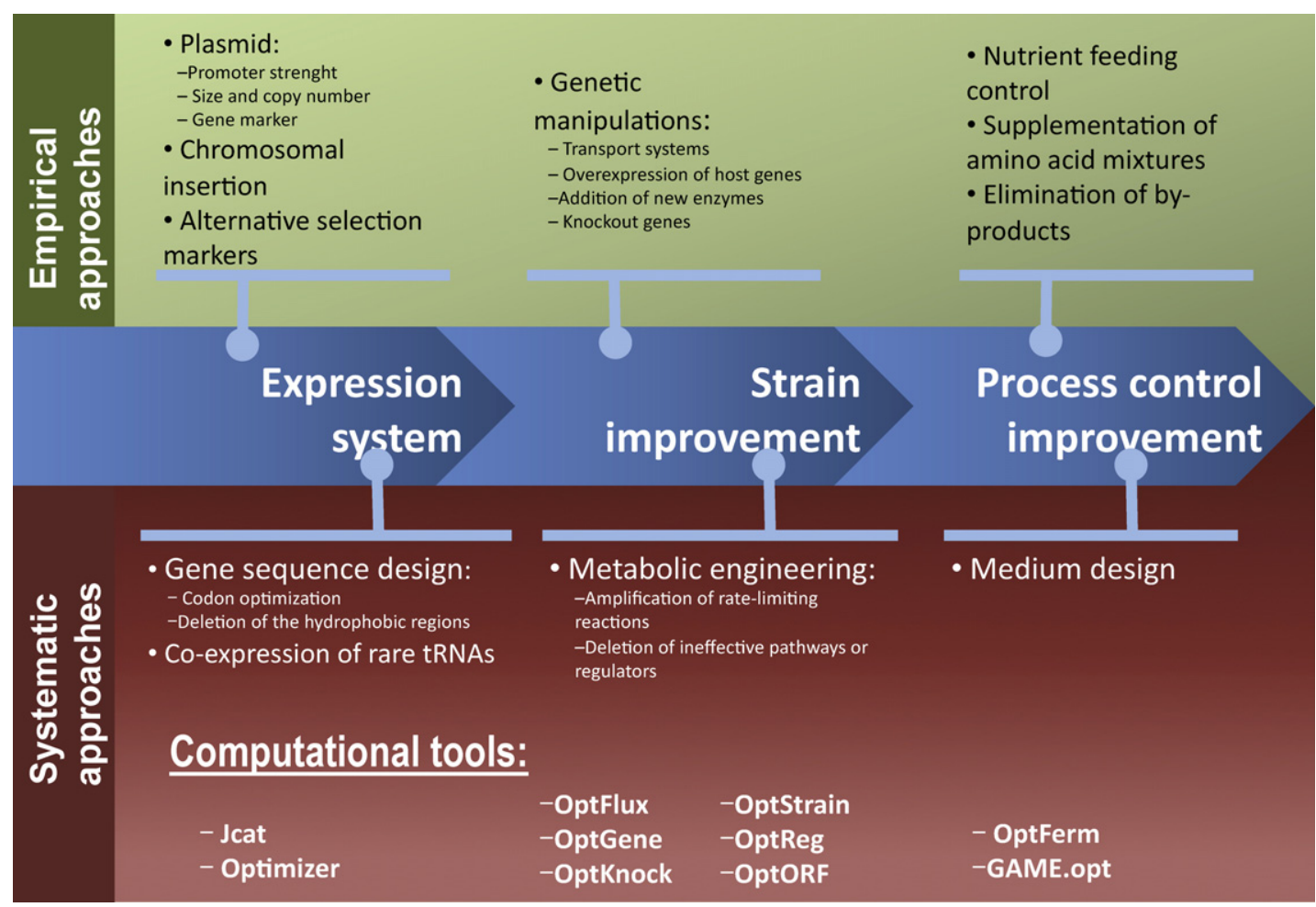

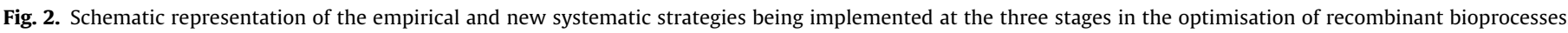

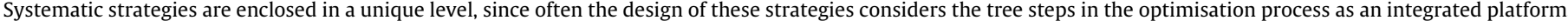

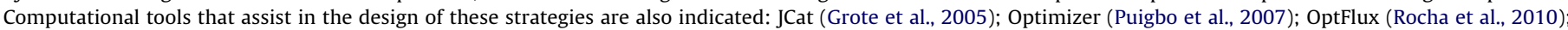

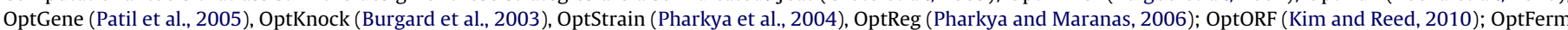
(Rocha et al., 2009); GAME.opt (Link and Weuster-Botz, 2006).

maximization) (Edwards et al., 2002; Kauffman et al., 2003; Price et al., 2003; Raman and Chandra, 2009; Varma and Palsson, 1994). FBA explores the metabolic capabilities of cells and predicts their phenotype under defined environmental conditions (e.g. aerobiosis/anaerobiosis or with different carbon sources). Additionally, these stoichiometric-based models can also be used to predict gene deletions in the wild-type strain that would maximize the production rate of a desired metabolic product. To find feasible metabolic flux distributions that fulfil these conditions it is possible to use several optimization methods: OptGene (Patil et al., 2005), OptKnock (Burgard et al., 2003), OptStrain (Pharkya et al., 2004), OptReg (Pharkya and Maranas, 2006) and more recently OptORF (Kim and Reed, 2010). Although the availability of computational tools is increasing, the successful application of these stoichiometric models has been limited to the design of strains for the production of metabolic end-products, such as: the overproduction of purine nucleosides, riboflavin, and folic acid in Bacillus subtilis (Sauer et al., 1998); the enhancement of the biosynthesis of sesquiterpenes in the yeast Saccharomyces cerevisiae (Asadollahi et al., 2009); the improved bioethanol production in Saccharomyces cerevisiae (Bro et al., 2006); the overproduction of threonine in E. coli (De Atauri et al., 2009); or the production of vanillin in baker's yeast (Brochado et al., 2010). These in silico approaches are still inadequate for the optimization of recombinant protein production, since the dynamics behind recombinant processes makes difficult to simulate and predict the behaviour of the system. For this reason, most modelling approaches to study recombinant bioprocesses have been based on kinetic descriptions that reproduce the physiological behaviour of cells. However, it is unfeasible to represent all levels of a system using this type of models. Not only because there is a large number of cellular components that would be needed to be represented in the model, but also because it is impossible to describe the mathematical relationships between components participating in such cellular activities, at least in the current state-of-art Despite all, E. coli strains have been metabolically engineered using approaches to obtain optimal phenotypes for the production of end-products, which can be of interest to the improvement of the production of recombinant products, by increasing precursors and cofactors availability (Chemler et al., 2010; Fowler et al., 2009; Park et al., 2007). The metabolically engineered strain carrying $\Delta p g i$, $\Delta p p c$ and $\Delta p l d A$ deletions is one of the best examples that demonstrate the advantages of using stoichiometric models to identify combinations of gene knockouts to improve the NADPH availability in E. coli (Chemler et al., 2010). A constraint-based metabolic model combined with an evolutionary-based optimization method was used to investigate the phenotype of knockout candidates that maximizes the production rate of NADPH while also maximizing for growth, i.e. biomass product coupled yield (BPCY). The BPCY objective function avoids selecting mutants with high specific production rates but that are not viable. Though the overexpression of a recombinant protein was not accounted in the model, this approach showed some advantages because it improves the overall NADPH production in the mutant strain, which has been identified as a limiting resource during recombinant bioprocesses.

Another example is the rationally engineered $E$. coli strain to overproduce L-valine by introducing the following genetic modifications: $\Delta a c e \mathrm{~F}, \Delta m d h$, and $\Delta p f k$ A. This strain can also be interesting for the overproduction of recombinant proteins that have a sequence rich in L-valine. As previously discussed, the amino acid sequence of the recombinant protein influences the physiological behaviour of the host strain due to shortages in the intracellular amino acid pools, especially for least abundant amino acids. However, this is not always so straightforward and modelling strategies to predict the amino acid shortages during recombinant processes should be first implemented. Sarkandy et al. (2010) developed an amino acid supplementation strategy based on the simulation of 
a stoichiometric model that could predict which amino acids are most needed to enhance the production of IL-2 (interleukin-2 as a model protein) in a fed-batch high-cell-density culture. The most effective amino acid mixture was found to be leucine, aspartic acid and glycine, which increased the production of IL-2 almost twofold (Sarkandy et al., 2010). Seemingly, a modelling approach based on a stoichiometric model combined with kinetic-based descriptions for the production of a recombinant protein and cell growth was proposed (Carneiro et al., 2011a). This model allows to follow the withdrawn of amino acids for biomass and recombinant protein formation along the cultivation process and to estimate which amino acids are the first to become limited. More importantly, these models enable to couple the modelling of cultivation strategies with the metabolic engineering of cells. These systematic approaches might be some of the earliest attempts to overcome the metabolic burden of recombinant processes by combining different aspects of the bioprocesses optimization problem.

\section{Concluding remarks}

The success of recombinant bioprocesses depends on the understanding of the metabolic responses to the burden imposed by additional drainages of metabolic resources toward the production of recombinant material. In this review, strategies that have been developed, either to cope with the shortage of metabolic resources or the control of the metabolism overflow, were addressed. Although most of these strategies were able to improve the recombinant protein production, reduced biomass yields and the accumulation of metabolic by-products were also observed. Therefore, alternative strategies that allow to manipulate these recombinant systems in a more efficient way are in great need.

Systems biology and particularly metabolic engineering have been valuable to rationally design microbial strains for the production of many products of interest (Sauer et al., 1998; Asadollahi et al., 2009; Bro et al., 2006; De Atauri et al., 2009; Brochado et al., 2010). So far, modeling approaches have mostly applied constrained-based models, which seem to work well in the design of strains for the improved production of chemicals that belong to the central carbon metabolism. Recombinant processes are far more complex, since the expression of recombinant proteins is generally plasmid-based, meaning that the interaction with the central carbon metabolism is not straightforward to understand and to model. However, the combination of dynamic and stoichiometric models can be useful for the simulation of these cellular processes, since the dynamics of the recombinant synthesis can be easily captured, as well as the growth-dependent metabolic behavior of cells. Metabolic models, like those reconstructed for E. coli, e.g. the iJR904 (Reed et al., 2003) and the iAF1260 (Feist et al., 2007), when combined with mechanistic models can offer a more comprehensive representation of the cellular organization.

\section{Acknowledgements}

This work was partially supported by the MIT-Portugal Program in Bioengineering (MIT-Pt/BS-BB/0082/2008), the research project HeliSysBio-Molecular Systems Biology Helicobacter pylori (FCT PTDC/EBB-EBI/104235/2008) and a PhD grant from Portuguese FCT (Fundação para a Ciência e Tecnologia)(SFRH/BD/22863/2005).

\section{References}

Aldor, I.S., Krawitz, D.C., Forrest, W., Chen, C., Nishihara, J.C., Joly, J.C., Champion, K.M., 2005. Proteomic profiling of recombinant Escherichia coli in high-cell-density fermentations for improved production of an antibody fragment biopharmaceutical. Applied and Environmental Microbiology 71, 1717-1728.

Andersen, D.C., Krummen, L., 2002. Recombinant protein expression for therapeutic applications. Current Opinion in Biotechnology 13, 117-123.
Andersson, L., Yang, S., Neubauer, P., Enfors, S.-O., 1996. Impact of plasmid presence and induction on cellular responses in fed batch cultures of Escherichia coli. Journal of Biotechnology 46, 255-263.

Angov, E., Hillier, C.J., Kincaid, R.L., Lyon, J.A., 2008. Heterologous protein expression is enhanced by harmonizing the codon usage frequencies of the target gene with those of the expression host. PLoS One 3, e2189.

Aristidou, A.A., San, K.Y., Bennett, G.N., 1995. Metabolic engineering of Escherichia coli to enhance recombinant protein production through acetate reduction. Biotechnology Progress 11, 475-478.

Artsimovitch, I., Patlan, V., Sekine, S.I., Vassylyeva, M.N., Hosaka, T., Ochi, K., Yokoyama, S., Vassylyev, D.G., 2004. Structural basis for transcription regulation by alarmone ppGpp. Cell 117, 299-310.

Asadollahi, M.A., Maury, J., Patil, K.R., Schalk, M., Clark, A., Nielsen, J., 2009. Enhancing sesquiterpene production in Saccharomyces cerevisiae through in silico driven metabolic engineering. Metabolic Engineering 11, 328-334.

Bailey, J.E., 1993. Host-vector interactions in Escherichia coli. Advances in Biochemical Engineering Biotechnology 48, 29-52.

Baneyx, F., 1999. Recombinant protein expression in Escherichia coli. Current Opinion in Biotechnology 10, 411-421.

Bentley, W.E., Kompala, D.S., 1990. Optimal induction of protein synthesis in recombinant bacterial cultures. Annals of the New York Academy of Sciences 589, 121-138.

Bentley, W.E., Mirjalili, N., Andersen, D.C., Davis, R.H., Kompala, D.S., 1990. Plasmidencoded protein - the principal factor in the metabolic burden associated with recombinant bacteria. Biotechnology and Bioengineering 35, 668-681.

Birnbaum, S., Bailey, J.E., 1991. Plasmid presence changes the relative levels of many host cell proteins and ribosome components in recombinant Escherichia coli. Biotechnology and Bioengineering 37, 736-745.

Blaas, L., Musteanu, M., Eferl, R., Bauer, A., Casanova, E., 2009. Bacterial artificial chromosomes improve recombinant protein production in mammalian cells. BMC Biotechnology 9.

Bonomo, J., Gill, R.T., 2005. Amino acid content of recombinant proteins influences the metabolic burden response. Biotechnology and Bioengineering 90, 116-126.

Bro, C., Regenberg, B., Forster, J., Nielsen, J., 2006. In silico aided metabolic engineering of Saccharomyces cerevisiae for improved bioethanol production. Metabolic Engineering 8, 102-111.

Brochado, A.R., Matos, C., Moller, B.L., Hansen, J., Mortensen, U.H., Patil, K.R., 2010. Improved vanillin production in baker's yeast through in silico design. Microbial Cell Factories 9.

Bulter, T., Bernstein, J.R., Liao, J.C., 2003. A perspective of metabolic engineering strategies: moving up the systems hierarchy. Biotechnology and Bioengineering $84,815-821$.

Burgard, A.P., Pharkya, P., Maranas, C.D., 2003. OptKnock: A bilevel programming framework for identifying gene knockout strategies for microbial strain optimization. Biotechnology and Bioengineering 84, 647-657.

Burgess-Brown, N.A., Sharma, S., Sobott, F., Loenarz, C., Oppermann, U., Gileadi, O., 2008. Codon optimization can improve expression of human genes in Escherichia coli. A multi-gene study. Protein Expression and Purification 59, 94102.

Calderone, T.L., Stevens, R.D., Oas, T.G., 1996. High-level misincorporation of lysine for arginine at AGA codons in a fusion protein expressed in Escherichia coli. Journal of Molecular Biology 262, 407-412.

Carneiro, S., Ferreira, E.C., Rocha, I., 2011a. A systematic modeling approach to elucidate the triggering of the stringent response in recombinant E. coli systems. Advances in Intelligent and Soft Computing 93, 313-320.

Carneiro, S., Villas-Boas, S.G., Ferreira, E.C., Rocha, I., 2011b. Metabolic footprint analysis of recombinant Escherichia coli strains during fed-batch fermentations. Molecular Biosystems 7, 899-910.

Castano-Cerezo, S., Pastor, J.M., Renilla, S., Bernal, V., Iborra, J.L., Canovas, M., 2009. An insight into the role of phosphotransacetylase $(p t a)$ and the acetate/acetyl-CoA node in Escherichia coli. Microbial Cell Factories 8, 54.

Chang, D.E., Shin, S., Rhee, J.S., Pan, J.G., 1999. Acetate metabolism in a pta mutant of Escherichia coli W3110: importance of maintaining acetyl coenzyme A flux for growth and survival. Journal of Bacteriology 181, 6656-6663.

Chatterji, D., Fujita, N., Ishihama, A., 1998. The mediator for stringent control, ppGpp, binds to the beta-subunit of Escherichia coli RNA polymerase. Genes to Cells 3, 279-287.

Chemler, J.A., Fowler, Z.L., McHugh, K.P., Koffas, M.A., 2010. Improving NADPH availability for natural product biosynthesis in Escherichia coli by metabolic engineering. Metabolic Engineering 12, 96-104.

Chen, H.T., Lin, M.S., Hou, S.Y., 2008. Multiple-copy-gene integration on chromosome of Escherichia coli for beta-galactosidase production. Korean Journal of Chemical Engineering 25, 1082-1087.

Chiang, C.J., Chen, P.T., Chao, Y.P., 2008. Replicon-free and markerless methods for genomic insertion of DNAs in phage attachment sites and controlled expression of chromosomal genes in Escherichia coli. Biotechnology and Bioengineering 101, 985-995.

Choi, J.H., Keum, K.C., Lee, S.Y., 2006. Production of recombinant proteins by high cell density culture of Escherichia coli. Chemical Engineering Science 61, 876-885.

Choi, J.H., Lee, S.J., Lee, S.J., Lee, S.Y., 2003. Enhanced production of insulin-like growth factor I fusion protein in Escherichia coli by coexpression of the down-regulated genes identified by transcriptome profiling. Applied Environment and Microbiology 69, 4737-4742.

Choi, J.H., Lee, S.Y., 2004. Secretory and extracellular production of recombinant proteins using Escherichia coli. Applied Microbiology and Biotechnology 64, 625-635. 
Chou, C.H., Bennett, G.N., San, K.Y., 1994. Effect of modified glucose uptake using genetic engineering techniques on high-level recombinant protein production in Escherichia coli dense cultures. Biotechnology and Bioengineering 44, 952-960.

Chou, C.P., 2007. Engineering cell physiology to enhance recombinant protein production in Escherichia coli. Applied Microbiology and Biotechnology 76, 521-532.

Corchero, J.L., Villaverde, A., 1998. Plasmid maintenance in Escherichia coli recombinant cultures is dramatically, steadily, and specifically influenced by features of the encoded proteins. Biotechnology and Bioengineering 58, 625-632.

Covert, M.W., Schilling, C.H., Famili, I., Edwards, J.S., Goryanin, I.I., Selkov, E., Palsson, B.O., 2001. Metabolic modeling of microbial strains in silico. Trends in Biochemical Sciences 26, 179-186.

Curless, C., Pope, J., Tsai, L., 1990. Effect of preinduction specific growth rate on recombinant alpha consensus interferon synthesis in Escherichia coli. Biotechnology Progress 6, 149-152.

De Anda, R., Lara, A.R., Hernandez, V., Hernandez-Montalvo, V., Gosset, G., Bolivar, F., Ramirez, O.T., 2006. Replacement of the glucose phosphotransferase transport system by galactose permease reduces acetate accumulation and improves process performance of Escherichia coli for recombinant protein production without impairment of growth rate. Metabolic Engineering 8, 281-290.

De Atauri, P., Rodriguez-Prados, J.C., Maury, J., Ortega, F., Portais, J.C., Chassagnole, C., Acerenza, L., Lindley, N.D., Cascante, M., 2009. In silico strategy to rationally engineer metabolite production: a case study for threonine in Escherichia coli. New Biotechnology 25, S358.

de Oliveira, J.E., Soares, C.R., Peroni, C.N., Gimbo, E., Camargo, I.M., Morganti, L., Bellini, M.H., Affonso, R., Arkaten, R.R., Bartolini, P., Ribela, M.T., 1999. High-yield purification of biosynthetic human growth hormone secreted in Escherichia coli periplasmic space. Journal of Chromatography A 852, 441-450.

Dedhia, N., Richins, R., Mesina, A., Chen, W., 1997. Improvement in recombinant protein production in ppGpp-deficient Escherichia coli. Biotechnology and Bioengineering $53,380-386$.

Del Jr., T.B., Ward, J.M., Hodgson, J., Gershater, C.J., Edwards, H., Wysocki, L.A., Watson, F.A., Sathe, G., Kane, J.F., 1995. Effects of a minor isoleucyl tRNA on heterologous protein translation in Escherichia coli. Journal of Bacteriology 177, 7086-7091.

Demain, A.L., Adrio, J.L., 2008. Strain improvement for production of pharmaceuticals and other microbial metabolites by fermentation. Progress in Drug Research 65, 251, 253-251, 289.

Demain, A.L., Vaishnav, P., 2009. Production of recombinant proteins by microbes and higher organisms. Biotechnology Advances 27, 297-306.

Deuschle, U., Kammerer, W., Gentz, R., Bujard, H., 1986. Promoters of Escherichia coli: a hierarchy of in vivo strength indicates alternate structures. EMBO Journal 5 2987-2994.

Dittrich, C.R., Vadali, R.V., Bennett, G.N., San, K.Y., 2005. Redistribution of metabolic fluxes in the central aerobic metabolic pathway of $E$. coli mutant strains with deletion of the ackA-pta and poxB pathways for the synthesis of isoamyl acetate. Biotechnology Progress 21, 627-631.

Dong, H.J., Nilsson, L., Kurland, C.G., 1995. Gratuitous overexpression of genes in Escherichia coli leads to growth inhibition and ribosome destruction. Journal of Bacteriology 177, 1497-1504.

Doyle, M.V., Lee, M.T., Fong, S., 1985. Comparison of the biological activities of human recombinant interleukin-2(125) and native interleukin-2. Journal of Biological Response Modifiers 4, 96-109.

Duerrschmid, K., Reischer, H., Schmidt-Heck, W., Hrebicek, T, Guthke, R, Rizzi, A Bayer, K., 2008. Monitoring of transcriptome and proteome profiles to investigate the cellular response of $E$. coli towards recombinant protein expression under defined chemostat conditions. Journal of Biotechnology 135, 34-44.

Edwards, J.S., Covert, M., Palsson, B., 2002. Metabolic modelling of microbes: the flux-balance approach. Environmental Microbiology 4, 133-140.

Eiteman, M.A., Altman, E., 2006. Overcoming acetate in Escherichia coli recombinant protein fermentations. Trends in Biotechnology 24, 530-536.

Enfors, S.O., Jahic, M., Rozkov, A., Xu, B., Hecker, M., Jurgen, B., Kruger, E., Schweder, T., Hamer, G., O’Beirne, D., Noisommit-Rizzi, N., Reuss, M., Boone, L., Hewitt C., McFarlane, C., Nienow, A., Kovacs, T., Tragardh, C., Fuchs, L., Revstedt, J. Friberg, P.C., Hjertager, B., Blomsten, G., Skogman, H., Hjort, S., Hoeks, F., Lin, H.Y., Neubauer, P., van der Lans, R., Luyben, K., Vrabel, P., Manelius, A., 2001. Physiological responses to mixing in large scale bioreactors. Journal of Biotechnology $85,175-185$.

Farmer, W.R., Liao, J.C., 1997. Reduction of aerobic acetate production by Escherichia coli. Applied and Environmental Microbiology 63, 3205-3210.

Feist, A.M., Henry, C.S., Reed, J.L., Krummenacker, M., Joyce, A.R., Karp, P.D., Broadbelt, L.J., Hatzimanikatis, V., Palsson, B.O., 2007. A genome-scale metabolic reconstruction for Escherichia coli K-12 MG1655 that accounts for 1260 ORFs and thermodynamic information. Molecular Systems Biology 3, 121.

Ferrer-Miralles, N., Domingo-Espin, J., Corchero, J.L., Vazquez, E., Villaverde, A., 2009 Microbial factories for recombinant pharmaceuticals. Microbial Cell Factories 8 , 17.

Flores, N., Leal, L., Sigala, J.C., de, A.R., Escalante, A., Martinez, A., Ramirez, O.T., Gosset, G., Bolivar, F., 2007. Growth recovery on glucose under aerobic conditions of an Escherichia coli strain carrying a phosphoenolpyruvate:carbohydrate phosphotransferase system deletion by inactivating arcA and overexpressing the genes coding for glucokinase and galactose permease. Journal of Molecular Microbiology and Biotechnology 13, 105-116.

Flores, S., de Anda-Herrera, R., Gosset, G., Bolivar, F.G., 2004. Growth rate recovery of Escherichia coli cultures carrying a multicopy plasmid, by engineering of the pentose-phosphate pathway. Biotechnology and Bioengineering 87, 485494
Fowler, Z.L., Gikandi, W.W., Koffas, M.A., 2009. Increased malonyl coenzyme A biosynthesis by tuning the Escherichia coli metabolic network and its application to flavanone production. Applied and Environmental Microbiology 75 5831-5839.

Glick, B.R., 1995. Metabolic load and heterologous gene expression. Biotechnology Advances 13, 247-261.

Gnoth, S., Jenzsch, M., Simutis, R., Lubbert, A., 2008. Control of cultivation processes for recombinant protein production: a review. Bioprocess and Biosystems Engineering 31, 21-39.

Gregory, M.E., Turner, C., 1993. Open-loop control of specific growth rate in fed-batch cultures of recombinant $E$. coli. Biotechnology Techniques 7, 889-894.

Grote, A., Hiller, K., Scheer, M., Munch, R., Nortemann, B., Hempel, D.C., Jahn, D., 2005. JCat: a novel tool to adapt codon usage of a target gene to its potential expression host. Nucleic Acids Research 33, W526-W531.

Gustafsson, C., Govindarajan, S., Minshull, J., 2004. Codon bias and heterologous protein expression. Trends in Biotechnology 22, 346-353.

Gustafsson, C., Minshull, J., Govindarajan, S., Ness, J., Villalobos, A., Welch, M., 2012. Engineering genes for predictable protein expression. Protein Expression and Purification 83, 37-46.

Haddadin, F.T., Harcum, S.W., 2005. Transcriptome profiles for high-cell-density recombinant and wild-type Escherichia coli. Biotechnology and Bioengineering 90, 127-153.

Hale, R.S., Thompson, G., 1998. Codon optimization of the gene encoding a domain from human type 1 neurofibromin protein results in a threefold improvement in expression level in Escherichia coli. Protein Expression and Purification 12, $185-188$

Han, J.H., Choi, Y.S., Kim, W.J., Jeon, Y.H., Lee, S.K., Lee, B.J., Ryu, K.S., 2010. Codon optimization enhances protein expression of human peptide deformylase in $E$. coli. Protein Expression and Purification 70, 224-230.

Han, M.J., Lee, J.W., Lee, S.Y., 2011. Understanding and engineering of microbial cells based on proteomics and its conjunction with other omics studies. Proteomics $11,721-743$.

Harcum, S.W., Ramirez, D.M., Bentley, W.E., 1992. Optimal nutrient feed policies for heterologous protein production. Applied Biochemistry and Biotechnology 34-5, 161-173.

Heyland, J., Blank, L.M., Schmid, A., 2011. Quantification of metabolic limitations during recombinant protein production in Escherichia coli. Journal of Biotechnology $155,178-184$.

Hsiao, J., Ahluwalia, M., Kaufman, J., Clem, T.R., Shiloach, J., 1990. Adaptive control strategy for maintaining dissolved oxygen concentration in high density growth of recombinant E. coli. Annals of New York Academy of Sciences, 321 333.

Hsu, E., Osslund, T., Nybo, R., Chen, B.L., Kenney, W.C., Morris, C.F., Arakawa, T., Narhi, L.O., 2006. Enhanced stability of recombinant keratinocyte growth factor by mutagenesis. Protein Engineering Design and Selection 19, 147-153.

Jana, S., Deb, J.K., 2005. Strategies for efficient production of heterologous proteins in Escherichia coli. Applied Microbiology and Biotechnology 67 289-298.

Jeon, E., Lee, S., Won, J.I., Han, S.O., Kim, J., Lee, J., 2011. Development of Escherichia coli MG1655 strains to produce long chain fatty acids by engineering fatty acid synthesis (FAS) metabolism. Enzyme and Microbial Technology 49, 44-51.

Jinho, S., Bailey, J.E., 1985. Effects of recombinant plasmid content on growth properties and cloned gene product formation in Escherichia coli. Biotechnology and Bioengineering 27, 1668-1674.

Jones, K.L., Kim, S.W., Keasling, J.D., 2000. Low copy plasmids can perform as well as or better than high copy plasmids for metabolic engineering of bacteria. Metabolic Engineering 2, 328-338.

Jonet, M.A., Mahadi, N.M., Murad, A.M.A., Rabu, A., Bakar, F.D.A., Rahim, R.A. Low, K.O., Illias, R., 2012. Optimization of a heterologous signal peptide by site-directed mutagenesis for improved secretion of recombinant proteins in Escherichia coli. Journal of Molecular Microbiology and Biotechnology 22, 48-58.

Kamionka, M., 2011. Engineering of therapeutic proteins production in Escherichia coli. Current Pharmaceutical Biotechnology 12, 268-274.

Kane, J.F., 1995. Effects of rare codon clusters on high-level expression of heterologous proteins in Escherichia coli. Current Opinion in Biotechnology 6, 494-500.

Kauffman, K.J., Prakash, P., Edwards, J.S., 2003. Advances in flux balance analysis. Current Opinion in Biotechnology 14, 491-496.

Kim, J., Reed, J.L., 2010. OptORF: Optimal metabolic and regulatory perturbations for metabolic engineering of microbial strains. BMC Systems Biology 4, 53.

Kim, J.Y., Cha, H.J., 2003. Down-regulation of acetate pathway through antisense strategy in Escherichia coli: improved foreign protein production. Biotechnology and Bioengineering 83, 841-853.

Koh, B.T., Nakashimada, U., Pfeiffer, M., Yap, M.G.S., 1992. Comparison of acetate inhibition on growth of host and recombinant Escherichia coli K12 strains. Biotechnology Letters 14, 1115-1118.

Konstantinov, K., Kishimoto, M., Seki, T., Yoshida, T., 1990. A balanced DO-stat and its application to the control of acetic acid excretion by recombinant Escherichia coli. Biotechnology and Bioengineering 36, 750-758.

Konstantinov, K., Nishio, N., Seki, T., Yoshida, T., 1991. Physiologically motivated strategies for control of the fed-batch cultivation of recombinant Escherichia coli for phenylalanine production. Journal of Fermentation and Bioengineering 71, 350-355.

Krause, M., Ukkonen, K., Haataja, T., Ruottinen, M., Glumoff, T., Neubauer, A. Neubauer, P., Vasala, A., 2010. A novel fed-batch based cultivation method provides high cell-density and improves yield of soluble recombinant proteins in shaken cultures. Microbial Cell Factories 9, 11 
Lara, A.R., Caspeta, L., Gosset, G., Bolivar, F., Ramirez, O.T., 2008. Utility of an Escherichia coli strain engineered in the substrate uptake system for improved culture performance at high glucose and cell concentrations: an alternative to fed-batch cultures. Biotechnology and Bioengineering 99, 893-901.

Lara, A.R., Leal, L., Flores, N., Gosset, G., Bolivar, F., Ramirez, O.T., 2006a. Transcriptional and metabolic response of recombinant Escherichia coli to spatial dissolved oxygen tension gradients simulated in a scale-down system. Biotechnology and Bioengineering 93, 372-385.

Lara, A.R., Vazquez-Limon, C., Gosset, G., Bolivar, F., Lopez-Munguia, A., Ramirez, O.T., 2006b. Engineering Escherichia coli to improve culture performance and reduce formation of by-products during recombinant protein production under transient intermittent anaerobic conditions. Biotechnology and Bioengineering 94, 1164-1175.

Lee, D.H., Kim, S.G., Park, Y.C., Nam, S.W., Lee, K.H., Seo, J.H., 2007. Proteome analysis of recombinant Escherichia coli producing human glucagon-like peptide-1. Journal of Chromatography B: Analytical Technologies in the Biomedical and Life Sciences 849, 323-330.

Lee, S.Y., Lee, D.Y., Kim, T.Y., 2005. Systems biotechnology for strain improvement Trends in Biotechnology 23, 349-358.

Li, M., Wang, J., Geng, Y., Li, Y., Wang, Q., Liang, Q., Qi, Q., 2012. A strategy of gene overexpression based on tandem repetitive promoters in Escherichia coli. Microbial Cell Factories 11.

Link, H., Weuster-Botz, D., 2006. Genetic algorithm for multi-objective experimental optimization. Bioprocess and Biosystems Engineering 29, 385-390.

Lourenço, A., Carneiro, S., Pinto, J.P., Rocha, M., Ferreira, E.C., Rocha, I., 2011. A study of the short and long-term regulation of E. coli metabolic pathways. Journal of Integrative Bioinformatics 8, 183.

Luli, G.W., Strohl, W.R., 1990. Comparison of growth, acetate production, and acetate inhibition of Escherichia coli strains in batch and fed-batch fermentations. Applied and Environmental Microbiology 56, 1004-1011.

Martinez-Morales, F., Borges, A.C., Martinez, K., Shanmugam, K.T., Ingram, L.O., 1999 Chromosomal integration of heterologous DNA in Escherichia coli with precise removal of markers and replicons used during construction. Journal of Bacteriology $181,7143-7148$.

Mason, C.A., Bailey, J.E., 1989. Effects of plasmid presence on growth and enzyme activity of Escherichia coli DH5alpha. Applied Microbiology and Biotechnology 32, 54-60.

Neidhardt, F.C., Ingraham, J.L., Schaechter, M., 1990. Physiology of the Bacterial Cell-A Molecular Approach, 1st ed. Sinauer Associates, Sunderland, USA

Neubauer, P., Hofmann, K., Holst, O., Mattiasson, B., Kruschke, P., 1992. Maximizing the expression of a recombinant gene in Escherichia coli by manipulation of induction time using lactose as inducer. Applied Microbiology and Biotechnology 36, 739-744.

Neubauer, P., Winter, J., 2001. Expression and fermentation strategies for recombinant protein production in Escherichia coli. Recombinant Protein Production with Prokaryotic and Eukaryotic Cells. A Comparative View on Host Physiology., O.-W. Merten et al. (Ed.). Kluwer Academic Publisher, Dortrecht, The Netherlands, pp. 196-260.

Nicolas, C., Kiefer, P., Letisse, F., Kromer, J., Massou, S., Soucaille, P., Wittmann, C., Lindley, N.D., Portais, J.C., 2007. Response of the central metabolism of Escherichia coli to modified expression of the gene encoding the glucose-6phosphate dehydrogenase. FEBS Letters 581, 3771-3776.

Niemitalo, O., Neubauer, A., Liebal, U., Myllyharju, J., Juffer, A.H., Neubauer, P., 2005 Modelling of translation of human protein disulfide isomerase in Escherichia coli-A case study of gene optimisation. Journal of Biotechnology 120,11-24.

O'Rourke, E.C., Drummond, R.J., Creasey, A.A., 1984. Binding of 125I-labeled recombinant beta interferon (IFN-beta Ser17) to human cells. Molecular and Cellular Biology 4, 2745-2749.

Oh, M.K., Liao, J.C., 2000. DNA microarray detection of metabolic responses to protein overproduction in Escherichia coli. Metabolic Engineering 2, 201-209.

Park, J.H., Lee, K.H., Kim, T.Y., Lee, S.Y., 2007. Metabolic engineering of Escherichia coli for the production of L-valine based on transcriptome analysis and in silico gene knockout simulation. Proceedings of National Academy of Science of the United States of America 104, 7797-7802.

Park, S.J., Lee, S.Y., Cho, J., Kim, T.Y., Lee, J.W., Park, J.H., Han, M.J., 2005. Global physiological understanding and metabolic engineering of microorganisms based on omics studies. Applied Microbiology and Biotechnology 68, 567-579.

Patil, K.R., Rocha, I., Forster, J., Nielsen, J., 2005. Evolutionary programming as a platform for in silico metabolic engineering. BMC Bioinformatics 6.

Peretti, S.W., Bailey, J.E., 1987. Simulations of host-plasmid interactions in Escherichia coli - copy number, promoter strength, and ribosome binding site strength effects on metabolic activity and plasmid gene expression. Biotechnology and Bioengineering 29, 316-328.

Peti, W., Page, R., 2007. Strategies to maximize heterologous protein expression in Escherichia coli with minimal cost. Protein Expression and Purification 51, 1-10.

Pharkya, P., Burgard, A.P., Maranas, C.D., 2004. OptStrain: A computational framework for redesign of microbial production systems. Genome Research 14, 2367-2376.

Pharkya, P., Maranas, C.D., 2006. An optimization framework for identifying reaction activation/inhibition or elimination candidates for overproduction in microbial systems. Metabolic Engineering 8, 1-13.

Phue, J.N., Noronha, S.B., Hattacharyya, R., Wolfe, A.J., Shiloach, J., 2005. Glucose metabolism at high density growth of E. coli B and E. coli K: differences in metabolic pathways are responsible for efficient glucose utilization in $E$. coli $B$ as determined by microarrays and Northern blot analyses. Biotechnology and Bioengineering 90, 805-820.
Phue, J.N., Shiloach, J., 2004. Transcription levels of key metabolic genes are the cause for different glucose utilization pathways in E. coli B (BL21) and E. coli K (JM109). Journal of Biotechnology 109, 21-30.

Pilarek, M., Glazyrina, J., Neubauer, P., 2011. Enhanced growth and recombinant protein production of Escherichia coli by a perfluorinated oxygen carrier in miniaturized fed-batch cultures. Microbial Cell Factories 10, 50.

Pinske, C., Bonn, M., Kruger, S., Lindenstrauss, U., Sawers, R.G., 2011. Metabolic deficiences revealed in the biotechnologically important model bacterium Escherichia coli BL21(DE3). Plos One 6.

Plotkin, J.B., Kudla, G., 2011. Synonymous but not the same: the causes and consequences of codon bias. Nature Reviews Genetics 12, 32-42.

Price, N.D., Papin, J.A., Schilling, C.H., Palsson, B.O., 2003. Genome-scale microbial in silico models: the constraints-based approach. Trends in Biotechnology 21, $162-169$.

Puigbo, P., Guzman, E., Romeu, A., Garcia-Vallve, S., 2007. OPTIMIZER: a web server for optimizing the codon usage of DNA sequences. Nucleic Acids Research 35, W126-W131.

Raman, K., Chandra, N., 2009. Flux balance analysis of biological systems: applications and challenges. Briefings in Bioinformatics 10, 435-449.

Reed, J.L., Vo, T.D., Schilling, C.H., Palsson, B.O., 2003. An expanded genome-scale model of Escherichia coli K-12 (iJR904 GSM/GPR). Genome Biology 4, R54

Rocha, I., Maia, P., Evangelista, P., Vilaca, P., Soares, S., Pinto, J.P., Nielsen, J., Patil, K.R., Ferreira, E.C., Rocha, M., 2010. OptFlux: an open-source software platform for in silico metabolic engineering. BMC Systems Biology 4, 45.

Rocha, I., Veloso, A.C.A., Carneiro, S., Costa, R., Ferreira, E.C., 2008. Implementation of a specific rate controller in a fed-batch $E$. coli fermentation. In: Proceedings of the 17th IFAC (International Federation of Automatic Control) World Congress, Seoul, Korea, pp. 15565-15570.

Rocha, O., Maia, P., Rocha, I., Rocha, M., 2009 A Computational Platform for the Optimization of Fermentation Processes. Proc. of the European Simulation and Modelling Conference (ESM 2009).

Rozkov, A., Enfors, S.O., 1999. Stabilization of a proteolytically sensitive cytoplasmic recombinant protein during transition to downstream processing. Biotechnology and Bioengineering 62, 730-738.

Rozkov, A., Schweder, T., Veide, A., Enfors, S.O., 2000. Dynamics of proteolysis and its influence on the accumulation of intracellular recombinant proteins. Enzyme and Microbial Technology 27, 743-748.

Rozkov, A., vignone-Rossa, C.A., Ertl, P.F., Jones, P., O'Kennedy, R.D., Smith, J.J., Dale, J.W., Bushell, M.E., 2004. Characterization of the metabolic burden on Escherichia coli DH1 cells imposed by the presence of a plasmid containing a gene therapy sequence. Biotechnology and Bioengineering 88, 909-915.

Sandoval-Basurto, E.A., Gosset, G., Bolivar, F., Ramirez, O.T., 2005. Culture of Escherichia coli under dissolved oxygen gradients simulated in a two-compartment scale-down system: metabolic response and production of recombinant protein. Biotechnology and Bioengineering 89, 453463.

Sarkandy, S.Y., Khalilzadeh, R., Shojaosadati, S.A., Sadeghizadeh, M., Farnoud, A.M., Babaeipour, V., Maghsoudi, A., 2010. A novel amino acid supplementation strategy based on a stoichiometric model to enhance human IL-2 (interleukin-2) expression in high-cell-density Escherichia coli cultures. Biotechnology and Applied Biochemistry 57, 151-156.

Sauer, U., Cameron, D.C., Bailey, J.E., 1998. Metabolic capacity of Bacillus subtilis for the production of purine nucleosides, riboflavin, and folic acid. Biotechnology and Bioengineering 59, 227-238.

Saxena, P., Walker, J.R., 1992. Expression of argU, the Escherichia coli gene coding for a rare arginine tRNA. Journal of Bacteriology 174, 1956-1964.

Schreyer, R., Bock, A., 1980. Phosphoglucose isomerase from Escherischia coli K 10: purification, properties and formation under aerobic and anaerobic condition. Archives of Microbiology 127, 289-298.

Schweder, T., Lin, H.Y., Jurgen, B., Breitenstein, A., Riemschneider, S., Khalameyzer, V., Gupta, A., Buttner, K., Neubauer, P., 2002. Role of the general stress response during strong overexpression of a heterologous gene in Escherichia coli. Applied Microbiology and Biotechnology 58, 330-337.

Seo, Jin D., Chung, B.H., Hwang, Y.B., Park, Y.H., 1992. Glucose-limited fed-batch culture of Escherichia coli for production of recombinant human interleukin2 with the DO-stat method. Journal of Fermentation and Bioengineering 74, $196-198$.

Seo, J.H., Bailey, J.E., 1986. Continuous cultivation of recombinant Escherichia coli: Existence of an optimum dilution rate for maximum plasmid and gene product concentration. Biotechnology and Bioengineering 28, 1590-1594.

Seo, J.H., Bailey, J.E., 1985. Effects of recombinant plasmid content on growth properties and cloned gene product formation in Escherichia coli. Biotechnology and Bioengineering 27, 1668-1674.

Shiloach, J., Kaufman, J., Guillard, A.S., Fass, R., 1996. Effect of glucose supply strategy on acetate accumulation, growth, and recombinant protein production by Escherichia coli BL21 ( $\lambda$ DE3) and Escherichia coli JM109. Biotechnology and Bioengineering 49, 421-428.

Shimizu, N., Fukuzono, S., Fujimori, K., Nishimura, N., Odawara, Y., 1988. Fed-batch cultures of recombinant Escherichia coli with inhibitory substance concentration monitoring. Journal of Fermentation Technology 66, 187-191.

Silva, F., Queiroz, J.A., Domingues, F.C., 2012. Evaluating metabolic stress and plasmid stability in plasmid DNA production by Escherichia coli. Biotechnology Advances 30, 691-708.

Siurkus, J., Neubauer, P., 2011. Heterologous production of active ribonuclease inhibitor in Escherichia coli by redox state control and chaperonin coexpression. Microbial Cell Factories 10, 65. 
Son, Y.J., Phue, J.N., Trinh, L.B., Lee, S.J., Shiloach, J., 2011. The role of Cra in regulating acetate excretion and osmotic tolerance in E. coli K-12 and E. coli B at high density growth. Microbial Cell Factories 10, 52.

Sorensen, H.P., Mortensen, K.K., 2005. Advanced genetic strategies for recombinant protein expression in Escherichia coli. Journal of Biotechnology 115 113-128.

Spanjaard, R.A., Chen, K., Walker, J.R., van, D.J., 1990. Frameshift suppression at tandem AGA and AGG codons by cloned tRNA genes: assigning a codon to argU tRNA and T4 tRNA(Arg). Nucleic Acids Research 18, 5031-5036.

Suarez, D.C., Kilikian, B.V., 2000. Acetic acid accumulation in aerobic growth of recombinant Escherichia coli. Process Biochemistry 35, 1051-1055.

Summers, D.K., Beton, C.W., Withers, H.L., 1993. Multicopy plasmid instability: the dimer catastrophe hypothesis. Molecular Microbiology 8, 1031-1038.

Tao, Y., Cheng, Q., Kopatsis, A.D., 2012. Metabolic engineering for acetate control in large scale fermentation. Methods in Molecular Biology 834, 283-303.

Turner, C., Gregory, M.E., Turner, M.K., 1994. A study of the effect of specific growth rate and acetate on recombinant protein production of Escherichia coli JM107. Biotechnology Letters 16, 891-896.

Ukkonen, K., Vasala, A., Ojamo, H., Neubauer, P., 2011. High-yield production of biologically active recombinant protein in shake flask culture by combination of enzyme-based glucose delivery and increased oxygen transfer. Microbial Cell Factories 10, 107

Usui, Y., Hirasawa, T., Furusawa, C., Shirai, T., Yamamoto, N., Mori, H., Shimizu, H., 2012. Investigating the effects of perturbations to pgi and eno gene expression on central carbon metabolism in Escherichia coli using $13 \mathrm{C}$ metabolic flux analysis. Microbial Cell Factories 11, 87.

Valgepea, K., Adamberg, K., Nahku, R., Lahtvee, P.J., Arike, L., Vilu, R., 2010. Systems biology approach reveals that overflow metabolism of acetate in Escherichia coli is triggered by carbon catabolite repression of acetyl-CoA synthetase. BMC Systems Biology 4, 166.

Van de Walle, M., Shiloach, J., 1998. Proposed mechanism of acetate accumulation in two recombinant Escherichia coli strains during high density fermentation. Biotechnology and Bioengineering 57, 71-78.

Varma, A., Palsson, B.O., 1994. Metabolic flux balancing - basic concepts, scientific and practical use. Bio-Technology 12, 994-998.

Vidal, L., Pinsach, J., Striedner, G., Caminal, G., Ferrer, P., 2008. Development of an antibiotic-free plasmid selection system based on glycine auxotrophy for recombinant protein overproduction in Escherichia coli. Journal of Biotechnology 134, 127-136.
Wang, Y.H., Wu, S.L., Hancock, W.S., Trala, R., Kessler, M., Taylor, A.H., Patel, P.S. Aon, J.C., 2005. Proteomic profiling of Escherichia coli proteins under high cell density fed-batch cultivation with overexpression of phosphogluconolactonase. Biotechnology Progress 21, 1401-1411.

Wang, Z.J., Li, X.A., Shao, J.J., Wegrzyn, A., Wegrzyn, G., 2006. Effects of the presence of CoIEI plasmid DNA in Escherichia coli on the host cell metabolism. Microbial Cell Factories 5.

Wei, X.X., Shi, Z.Y., Li, Z.J., Cai, L., Wu, Q., Chen, G.Q., 2010. A mini-Mu transposonbased method for multiple DNA fragment integration into bacterial genomes. Applied Microbiology and Biotechnology 87, 1533-1541.

Wittmann, C., Weber, J., Betiku, E., Kromer, J., Bohm, D., Rinas, U., 2007. Response of fluxome and metabolome to temperature-induced recombinant protein synthesis in Escherichia coli. Journal of Biotechnology 132, 375-384.

Wong, M.S., Wu, S., Causey, T.B., Bennett, G.N., San, K.Y., 2008. Reduction of acetate accumulation in Escherichia coli cultures for increased recombinant protein production. Metabolic Engineering 10, 97-108

Xu, B., Jahic, M., Enfors, S.O., 1999. Modeling of overflow metabolism in batch and fed-batch cultures of Escherichia coli. Biotechnology Progress 15, 81-90.

Yang, B., Guo, Z., Huang, Y., Zhu, S., 2004. Codon optimization of MTS1 and its expression in Escherichia coli. Protein Expression and Purification 36, 307 311.

Yang, Y.T., Aristidou, A.A., San, K.Y., Bennett, G.N., 1999a. Metabolic flux analysis of Escherichia coli deficient in the acetate production pathway and expressing the Bacillus subtilis acetolactate synthase. Metabolic Engineering 1, 26-34.

Yang, Y.T., Bennett, G.N., San, K.Y., 1999b. Effect of inactivation of nuo and ackApta on redistribution of metabolic fluxes in Escherichia coli. Biotechnology and Bioengineering 65, 291-297.

Yoon, S.H., Han, M.J., Lee, S.Y., Jeong, K.J., Yoo, J.S., 2003. Combined transcriptome and proteome analysis of Escherichia coli during high cell density culture. Biotechnology and Bioengineering 81, 753-767.

Yu, C., Cao, Y.J., Zou, H.B., Xian, M., 2011. Metabolic engineering of Escherichia coli for biotechnological production of high-value organic acids and alcohols. Applied Microbiology and Biotechnology 89, 573-583.

Zhou, Z., Schnake, P., Xiao, L., Lal, A.A., 2004. Enhanced expression of a recombinant malaria candidate vaccine in Escherichia coli by codon optimization. Protein Expression and Purification 34, 87-94.

Zhu, J.F., Sanchez, A., Bennett, G.N., San, K.Y., 2011. Manipulating respiratory levels in Escherichia coli for aerobic formation of reduced chemical products. Metabolic Engineering 13, 704-712. 